\title{
KEMAMPUAN BAYAR, KEMAMPULABAAN DAN KONTRIBUSINYA DALAM MENOPANG PERMODALAN BANK PERKREDITAN RAKYAT
}

\author{
I Nyoman Nugraha Ardana Putra1, I Gede Mandra², \\ I Dewa Gde Bisma ${ }^{3}$, Sujadi ${ }^{4}$, Hery Susanto ${ }^{5}$ \\ ${ }^{1}$ Faculty of Economics and Business, Mataram University, Indonesia. \\ E-mail:nyoman.nugraha@unram.ac.id \\ ${ }^{2}$ Faculty of Economics and Business, Mataram University, Indonesia. \\ E-mail: mandragede@yahoo.co.id \\ ${ }^{3}$ Faculty of Economics and Business, Mataram University, Indonesia. \\ E-mail:idewagdebisma@unram.ac.id \\ ${ }^{4}$ Faculty of Economics and Business, Mataram University, Indonesia. \\ E-mail:sujadife@yahoo.com
}

${ }^{5}$ Faculty of Economics, Terbuka University, Indonesia. E-mail: herys@ecampus.ut.ac.id

\begin{tabular}{|c|c|}
\hline ARTICLE INFO & ABSTRACT \\
\hline 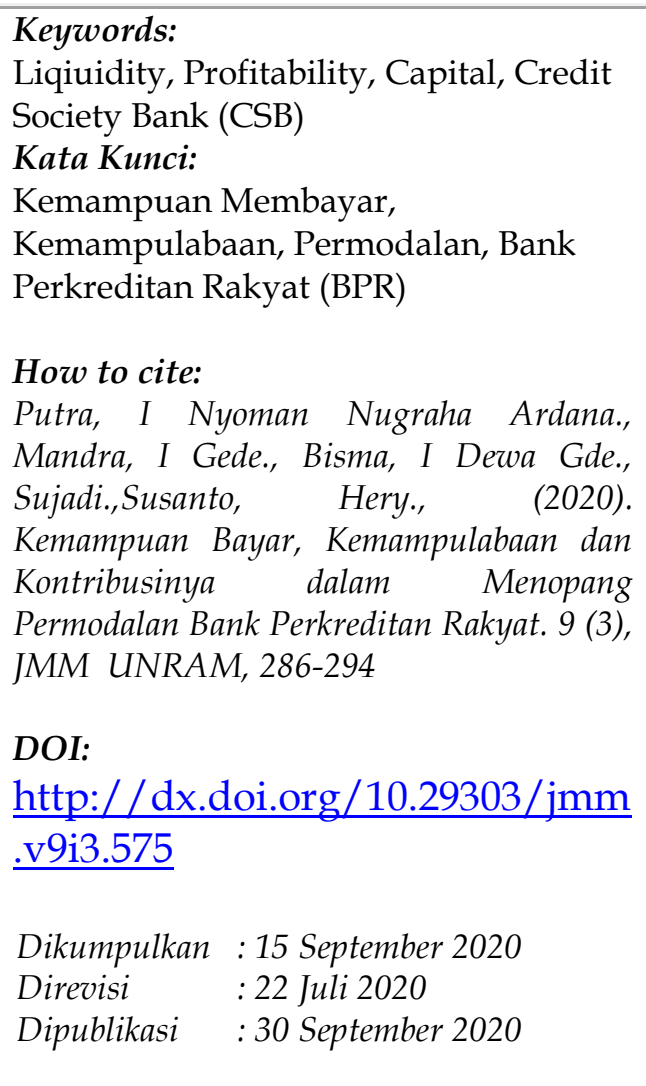 & $\begin{array}{l}\text { This Research aimed to analyze liquidity and profitability } \\
\text { to the capital of Conventional Credit Society Bank. The } \\
\text { associative method is using to analyze the problems that } \\
\text { arise. The location of observation on conventional credit } \\
\text { society bank (CSB) is in the province of West Nusa } \\
\text { Tenggara, which has experienced the level of capital. The } \\
\text { analysis used is path analysis. The results show liquidity } \\
\text { has opposite effects indirectly through the profitability of } \\
\text { capital. Those indicate the impact of the low liquidity but } \\
\text { through to increase efficiency and the capital. } \\
\text { Penelitian yang bertujuan untuk menganalisis variabel } \\
\text { pengaruh kemampuan bayar dan kemampulabaan } \\
\text { terhadap modal pada Bank Perkreditan Rakyat } \\
\text { konvensional. Jenis penelitian untuk menganalisis } \\
\text { masalah yang ada adalah asosiatif. Lokasi penelitian pada } \\
\text { Bank Perkreditan Rakyat Konvensional yang ada di } \\
\text { Provinsi Nusa Tenggara Barat (NTB) yang saat oni } \\
\text { mengalami permasalahan permodalan. Alat analisis yang } \\
\text { digunakan adalah path analysis. Hasil penelitian secara } \\
\text { keseluruhan kemampuan membayar berpengaruh negatif } \\
\text { secara tidak langsung terhadap modal melalui } \\
\text { kemampulabaan. Pengaruh negatif ini mengindikasikan } \\
\text { adanya tingkat kemampuan bayar yang rendah namun } \\
\text { melalui efisiensi dapat meningkatkan permodalan. }\end{array}$ \\
\hline
\end{tabular}


Copyright @ 2020. I Nyoman Nugraha Ardana Putra, I Gede Mandra, I Dewa Gde Bisma, Sujadi, Hery

Susanto. All rights reserved.

\section{PENDAHULUAN}

Fenomena menarik bagi BPR ditahun 2019 adalah adanya evaluasi pelaksanaan POJK No. 5/POJK.03/2015 tentang penyediaan modal minimum dan pemenuhan modal inti BPR. Modal inti yang meliputi modal inti utama dan modal inti tambahan serta modal kedua yaitu modal pelengkap. Peraturan tersebut ditetapkan pemerintah melalui OJK, agar BPR memiliki permodalan yang cukup dalam melayani masyarakat. Valencia dan Bolanos (2018) menyampaikan saat ini dunia membutuhkan standar kecukupan modal yang baru. Menurut Li dan Saiz (2018) bahwa risiko bank non sistematis disebabkan oleh risiko sistematis termasuk salah satunya peraturan pemerintah yang tujuannya mengatur tapi berdampak pada kemampuan perusahaan, termasuk permodalan.

Menurut Umar et al. (2017) bahwa likuiditas memiliki trade-off terhadap modal. Aktiva lancar mengukur rasio likuiditas, atau kemampuan bayar BPR yang mengukur seberapa likuid suatu bank dalam melayani nasabahnya dengan kata lain bagiamana bank tersebut di dalam menanggulangi kewajiban jangka pendeknya yang diukur dengan loan to deposit ratio (LDR). Sarath dan Pham (2017) menegaskan bahwa gangguan likuiditas justru terjadi pada bank swasta. LDR menunjukkan seberapa besar modal dan dana pihak ketiga yang dimiliki oleh BPR disalurkan ke masyarakat (Putra dkk., 2019). Likuiditas atau kemampuan membayar ini tentu sangat berdampak pada kemampulabaan (profitabilitas) karena pendapatan bank diperoleh dari penyaluran kredit. Terjadi kontradiksi hasil penelitian yaitu Afriyeni (2017) menyatakan bahwa kemampuan bayar tidak berpengaruh terhadap permodalan, namun penelitian Adelopo et al. (2018) dan Sulaeman et al. (2018) menunjukan bahwa kemampuan bayar berdampak positif pada modal.

Kemampulabaan merupakan rasio untuk menilai kemampuan perusahaan dalam mencari keuntungan. Hal ini ditunjukkan oleh laba yang dihasilkan dari penjualan dan pendapatan investasi. Intinya bahwa penggunaan rasio ini menunjukkan Kemampulabaan BPR (Putra, 2012). Kemampulabaan diukur dengan Return On Asset (ROA) yaitu rasio yang mengukur kemampuan perusahaan di dalam menghasilkan income dari pengelolaan aset (Putra, 2012). Aset tentu saja sangat terkait dengan permodalan perbankan.

Modal bank yang terdiri dari modal inti dan modal pelengkap. Permodalan bank biasanya menggunakan Capital Adequacy Ratio (CAR). Biasanya modal ini sangat terkait dengan kemampuan menghasilkan laba (profitabilitas). Berdasarkan Ramlall (2019) ketiganya termasuk peraturan yang bersifat ex ante yang membentuk kinerja bank. Ketiganya merupakan kemampuan membayar yang identik dengan total aktiva lancar, kemampulabaan yang setara dengan total laba dan modal yang sering dilihat dari total asset, maka diperoleh gambaran BPR di NTB sebagai berikut.

Tabel 1.1, Rata - rata perubahan Aktiva Lancar, Total Aktiva dan Laba BPR di NTB.

\begin{tabular}{|c|c|c|c|c|}
\hline \multirow{2}{*}{ No } & \multirow{2}{*}{ Keterangan } & \multicolumn{2}{|c|}{ Tahun } & \multirow{2}{*}{$\begin{array}{c}\text { Perubahan } \\
(\%)\end{array}$} \\
\hline & & 2017 & 2018 & \\
\hline 1 & Aktiva Lancar & Rp 9.019 .394 .000 & $\mathrm{Rp} 11.189 .922 .000$ & $24,06 \%$ \\
\hline 2 & Total Aktiva & $\operatorname{Rp} 45.562 .393 .000$ & $\operatorname{Rp} 49.064 .922 .000$ & $7,68 \%$ \\
\hline 3 & Laba & $\mathrm{Rp} \quad 858.628 .000$ & $\mathrm{Rp} \quad 1.289 .018 .000$ & $50,12 \%$ \\
\hline
\end{tabular}

(Sumber : Data OJK,diolah) 


\section{Jurnal Magister Manajemen Unram Vol. 9, No. 3 September 2020 NATIONALIY ACCREDITED JOURNAL - DECREE NO. 21/E/KPT/2018}

Tabel 1.1, menggambarkan perkembangan Aktiva Lancar, Total Aktiva, dan Laba BPR konvensional di NTB selama tahun 2017-2018. Aktiva Lancar BPR mengalami peningkatan sebesar 24,06\%, kemudian Total Aktiva BPR meningkat yaitu sebesar 7,68\%, dan Laba BPR juga ikut mengalami peningkatan yaitu sebesar 50,12\%. Berdasarkan latar belakang dan fenomena yang telah dikemukakan, peneliti tertarik untuk meneliti pengaruh likuiditas terhadap modal dengan profitabilitas sebagai variabel intervening pada BPR di Nusa Tenggara Barat. Oleh sebab itu, penelitian ini diberi judul "Dampak Kemampuan Bayar dan Kemampulabaan terhadap permodalan, BPR di Nusa Tenggara Barat".

\section{TINJAUAN PUSTAKA}

Sulaiman et al. (2018) Membedakan permodalan pada bank syariah dan bank konvensional di Malaysia. Bank syariah lebih menitikberatkan pada penguatan modal inti berupa modal sendiri, artinya dengan modal sendiri yang kuat maka bank dapat menutupi pendapatan yang tertunda berupa kredit bermasalah yang muncul. Pada bank konvensional dengan likuiditas yang dimiliki lebih berfokus pada peningkatan profitabilitasnya. Artinya Likuiditas berdampak pada permodalan baik secara langsung maupun tidak langsung melalui kemampulabaan.

Sahyouni dan Wang (2019) melakukan penelitian pada bank konvensional dan syariah pada Negara-negara yang tergabung dalam MENA sebanyak 18 negara antara tahun 2011 sampai dengan 2016. Bank Syariah menunjukan likuiditas yang lebih tinggi dibandingkan dengan bank konvensional. Hasil penelitian cukup menarik, ketika semakin tinggi likuiditas bank maka dikuti dengan semakin rendahnya profitabilitas. Berarti dapat disintesis dari Sulaeman et al. (2018) dan Sahyouni dan Wang (2019) bahwa permodalan bank cenderung meningkat ketika kemampulabaan meningkat.

Hal tersebut diperkuat dengan pendapat Adelopo et al. (2018) menguji pengaruh kondisi spesifik bank, ekonomi makro terhadap profitabilitas dan permodalan bank disaat krisis dunia tahun 2008. Selanjutnya periode penelitian sebelum krisis (1999-2006), selama periode krisis (2007-2009), dan setelah krisis (2010-2013). Ternyata kondisi spesifik bank yang salah satunya diukur dengan likuiditas berpengaruh positif baik sebelum, saat dan sesudah krisis. Hasil ini ternyata sesuai dengan Sulaeman et al. (2018) bahwa likuiditas positif terhadap modal. Jadi sintesis keduanya menunjukan dugaan yang kuat bahwa kemampuan bayar berpengaruh posituf terhadap permodalan.

Afriyeni (2017) menguji pengaruh likuiditas dengan menggunakan rasio LDR (Loan to Deposit Ratio) dan LAR (Loan to Asset Ratio) terhadap profitabilitas (Return on Asset) Bank Perkreditan Rakyat (BPR). Analisis data dilakukan dengan menggunakan regresi linier berganda. Hasil penelitian ini menunjukkan bahwa likuiditas yang diukur dengan rasio LDR dan LAR tidak terdapat pengaruh yang signifikan terhadap profitabilitas (Return on Assets) dari BPR di Kota Padang. Namun demikian berdasarkan yang disampaikan oleh Sulaeman et al. (2018), Adelopo et al. (2018) dan Sahyouni dan Wang (2019) bahwa kemampuan bayar berdampak positif pada modal melalui kemampulabaan.

\section{METODE PENELITIAN}

\subsection{Jenis Penelitian}

Penelitian ini adalah penelitian eksplanatif yang berusaha memprediksi seberapa besar kontribusi kemampuan membayar dan kemampulabaan dalam membentuk permodalan BPR yang tentunya saja akan bermanfaat bagi pengelola dalam pengambilan keputusan. 


\section{Jurnal Magister Manajemen Unram Vol. 9, No. 3 September 2020 NATIONALIY ACCREDITED JOURNAL - DECREE NO. 21/E/KPT/2018}

Penelitian eksplanatif dalam penelitian ini menggunakan strategi asosiatif kausalitas. Urgensi penggunaan Asosiatif Kausalitas adalah untuk melihat pengaruh variabel independen yaitu kemampuan bayar terhadap variabel dependen permodalan dengan kemampulabaan sebagai variable intervening, sehingga path analysis digunakan untuk menjawab tujuan penelitian.

\subsection{Lokasi Penelitian}

Objek penelitian adalah Bank Perkreditan Rakyat Konvensional yang ada di Provinsi Nusa Tenggara Barat (NTB). BPR di NTB memiliki tingkat likuiditas yang diukur dengan loan to deposit ratio (LDR) yang terus menurun setiap tahunnya yang berarti risiko likuiditas bertambah besar. Peningkatan risiko tersebut terjadi saat BPR di NTB sedang dalam proses mencukupi permodalannya, sesuai dengan aturan Otoritas Jasa Keuangan (OJK) No.5 Tahun 2015. Ada 32 Bank Perkreditan Rakyat yang beroperasi di NTB, terdapat 3 BPR yang merupakan BPR syariah (BPRS). Berarti terdapat 29 BPR konvensional yang ada di NTB yang melaporkan laporan keuangannya dari periode 2019.

\subsection{Definisi Operasional Variabel}

\subsubsection{Modal}

Capital Adequacy Ratio(CAR) yaitu perbandingan antara Modal dengan Aktiva Tertimbang Menurut Risiko yang dimiliki oleh Bank Perkreditan Rakyat Konvensional, atau modal dibagi derang risiko harta (Putra dkk., 2019) Rasio ini menunjukkan seberapa besar kemampuan yang dimiliki oleh modal bank di dalam menanggulangi aktiva - aktiva yang berisiko, semakin besar rasio ini maka semakin besar kemampuan permodalan bank di dalam menanggunglangi kemungkinan risiko dari aset yang dimiliki. Rasio ini dihitung dengan rumus berikut :

$$
C A R=\frac{\text { Modal }}{A T M R} \times 100 \%
$$

(Sembiring, 2010 dan Putra dkk., 2019).

\subsubsection{Kemampulabaan}

Kemampulabaan atau Profitabilitas menunjukkan kemampuan Bank Perkreditan Rakyat di dalam menghasilkan laba dari hasil operasi perusahaan. Profitabilitas dihitung dengan menggunakan Rasio Return On Assets atau sering disebut dengan Rasio ROA. Rasio ini merupakan perbandingan antara laba operasi yang dimiliki oleh Bank Perkreditan Rakyat dibandingkan dengan total aset yang dimiliki. Rumus untuk menghitung ROA Bank Perkreditan Rakyat adalah sebagai berikut :

$$
\text { ROA }=\frac{\text { Pendapatan Operasional }}{\text { Total Assets }} \times 100 \% \quad \text { (Putra,2013). }
$$

\subsubsection{Kemampuan Bayar}

Kemampuan bayar adalah risiko yang dimiliki oleh Bank Perkreditan Rakyat ketika BPR tersebut berhadapan dengan kemampuan untuk melakukan fungsi intermediasi. Risiko ini diukur dengan menggunakan besaran kredit yang disalurkan dibandingkan dengan simpanan dana pihak ketiga bank yaitu dengan rasio Loan Deposit Ratio (LDR). Rasio LDR dihitung menggunakan rumus :

$$
\mathrm{LDR}=\frac{\text { Kredit } \text { yang Disalurkan }}{\text { Simpanan }} \times 100 \% \quad \text { (Putra,dkk.;2019) }
$$

\subsection{Teknik Analisis Data}

Teknik analisis data dan pengujian hipotesis yang digunakan di dalam penelitian ini adalah menggunakan uji interaksi yaitu menggunakan path analysis, yang diselesaikan dengan analisis regresi linier berganda yang menguji persamaan regresi yang ada (Hair et al., 1995). 
Model yang digunakan untuk menguji hipotesis adalah :

$$
\begin{gathered}
Y=a+b 1 X 1+b 2 Z+e \\
Z=a+b 3 X 1+e
\end{gathered}
$$

Keterangan: $\mathrm{Y}=\mathrm{CAR}, \mathrm{a}=$ konstanta, $\mathrm{b} 1=$ koefisien regresi, $\mathrm{X} 1=\mathrm{LDR}, \mathrm{b} 2=$ koefisien regresi, $\mathrm{Z}=\mathrm{ROA}, \mathrm{b3}=$ Koefisien regresi, $\mathrm{e}=$ disturbance error

\section{HASIL PENELITIAN DAN PEMBAHASAN}

Penelitian ini menggunakan 2 persamaan regresi dalam menjawab pembentuk permodalan dalam Bank Perkreditan Rakyat. Persamaan pertama dan kedua dapat menjelaskan pengaruh kemampuan bayar dan kemampulabaan terhadap modal baik secara langsung maupun tidak langsung.

\section{a. Pengujian Persamaan Pertama}

awal adalah melakukan analisis berganda dengan Kemampuan Bayar dan Kemampulabaan sebagai variabel independen dan modal sebagai variabel dependen. Proxy yang digunakan adalah kemampuan bayar dengan loan to deposits ratio (LDR), kemampulbaan dengan Return on Assets (ROA) dan Modal dengan Capital Adequacy Ratio (CAR). Hasilnya adalah sebagai berikut :

Tabel 2, Hasil Regresi Persamaan Pertama

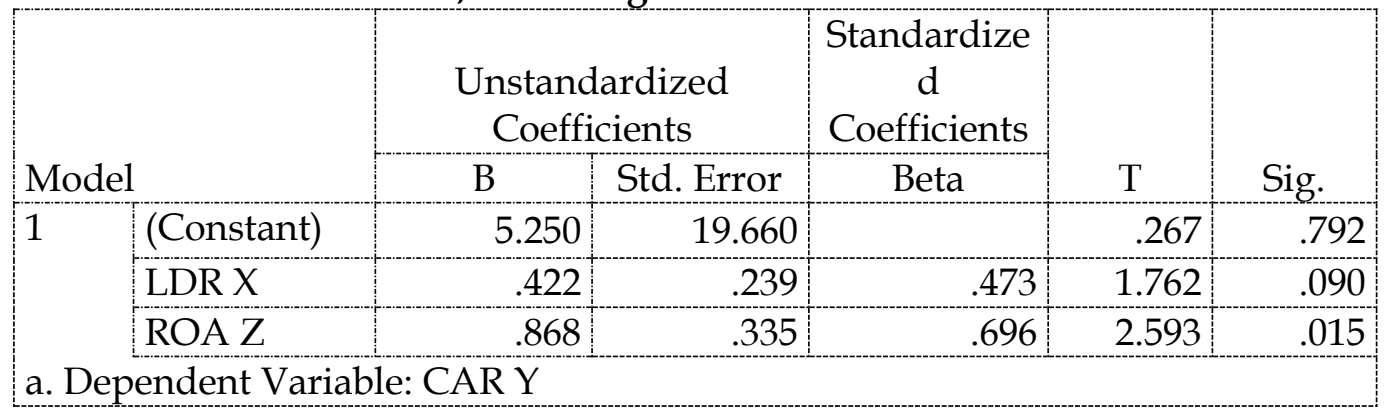

Hasil diatas dilihat dari nilai signifikansinya kemampuan bayar tidak berpengaruh terhadap modal, kemudian profitabilitas berpengaruh signifikan terhadap modal. Nilai koefisien likuiditas terhadap modal adalah sebesar 0,422 , dan nilai koefisien profitabilitas ke modal adalah 0,868 .

Berdasarkan hasil dari coefficients di atas dapat dikembangkan dengan menggunakan model persamaan regresi linier berganda sebagai berikut:

$\mathrm{CAR}=a+\mathrm{b} 1 \mathrm{X} 1+\mathrm{b} 2 \mathrm{Z}+\mathrm{e}$ apabila nilai pada Tabel 2 diatas disubsitusikan maka akan diperoleh nilai sebagai berikut:

$\mathrm{CAR}=5,250+0,422+0,868$

1. Koefisien Regresi X sebesar 0,422 artinya setiap kenaikan satu satuan LDR akan meningkatkan CAR sebesar 0,422. Dan sebaliknya, setiap penurunan satu satuan LDR, akan menurunkan CAR sebesar 0,422, dengan anggapan bahwa $Z$ tetap.

2. Koefisien Regresi $Z$ sebesar 0,868 artinya setiap kenaikan satu satuan ROA akan meningkatkan CAR sebesar 0,868. Dan sebaliknya, setiap penurunan satu satuan ROA, akan menurunkan CAR sebesar 0,868, dengan anggapan bahwa $X$ tetap.

Hasil estimasi variabel likuiditas sebesar nilai $t=1,762$ dengan probabilitas sebesar 0,090. Nilai signifikansi lebih dari tingkat signifikansi $(0,090>0,05)$. Menunjukkan bahwa variabel 
kemampuan bayar tidak berpengaruh terhadap modal Bank Perkreditan Rakyat di Nusa Tenggara Barat.

b. Pengujian Persamaan Kedua

Kemudian dilakukan analisis regresi berganda dengan likuditas sebagai variabel independen dan profitabilitas sebagai variabel dependen. Diperoleh hasil sebagai berikut:

Tabel 3 Hasil Regresi Untuk Persamaan Kedua

\begin{tabular}{|c|c|c|c|c|c|c|}
\hline & & \multicolumn{2}{|c|}{$\begin{array}{l}\text { Unstandardized } \\
\text { Coefficients }\end{array}$} & \multirow{2}{*}{$\begin{array}{l}\text { Standardize } \\
\text { d } \\
\text { Coefficients } \\
\text { Beta }\end{array}$} & \multirow[b]{2}{*}{$\mathrm{T}$} & \multirow[b]{2}{*}{ Sig. } \\
\hline \multicolumn{2}{|c|}{ Model } & B & Std. Error & & & \\
\hline \multirow[t]{2}{*}{1} & (Constant) & 47.056 & 6.761 & & 6.960 & .000 \\
\hline & LDR X & -.543 & .089 & -.760 & -6.076 & .000 \\
\hline
\end{tabular}

a. Dependent Variable: ROA Z

Hasil diatas bahwa memang kemampuan bayar terhadap kemampulabaan ini dilihat dari nilai signifikansinya mempunyai pengaruh, likuiditas berpengaruh signifikan terhadap profitabilitas. Lalu menententukan nilai koefisien, nilai koefisien ini diperoleh dari nilai unstandardized yaitu sebesar -0,543. Berdasarkan hasil dari coefficients di atas dapat dikembangkan dengan menggunakan model persamaan regresi sebagai berikut :

$\mathrm{ROA}=\mathrm{a}+\mathrm{b} 3 \mathrm{X} 1+\mathrm{e}$, atau berdasarkan hasil maka akan diperoleh nilai sebagai berikut :

$\mathrm{ROA}=47,056+(-0,543)$

Koefisien Regresi X sebesar -0,543 artinya setiap kenaikan satu satuan LDR akan meningkatkan ROA sebesar -0,543. Dan sebaliknya, setiap penurunan satu satuan LDR, akan menurunkan ROA sebesar -0,543.

c. Pengujian PATH Analysis

Berdasarkan kedua hasil perngujian kedua persamaan tersebut dapat dilakukan analisis jalaur (Path Analysis). Jalur yang diuji napak pada gambar berikut.

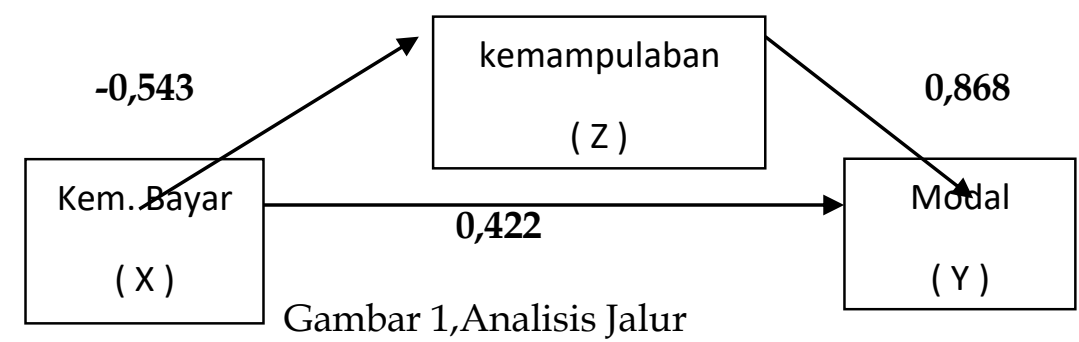

Hasil analisis diatas menunjukkan bahwa profitabilitas pure intervening, karena likuiditas tidak mempengaruhi modal, tapi likuiditas mempengaruhi modal secara tidak langsung melalui profitabilitas secara negatif.

Dari hasil analisis berdasarkan Gambar 1 likuiditas mempengruhi modal secara tidak langsung melalui profitabilitas secara negatif. Besarnya pengaruh tidak langsung $\mathrm{A} \times \mathrm{B}=$ $0,543 \times 0,868=-0,471$.

\section{d. Pembahasan}

\subsubsection{Pengaruh Likuiditas Terhadap Modal}

Berdasarkan uji parsial, pengaruh likuiditas terhadap modal diperoleh koefisien regresi $t=1,762$ dengan tingkat signifikansi 0,090. Jadi dapat dijelaskan bahwa likuiditas 
tidak berpengaruh terhadap modal sehingga hipotesis pertama tidak terbukti. Hasil penelitian ini bertentangan dengan Sari dkk (2016), menyatakan bahwa likuiditas berpengaruh positif dan signifikan terhadap modal.

Menurut Andini dan Yunita (2015), hal ini dikarenakan dana pihak ketiga yang merupakan unsur dalam perhitungan LDR tercatat pada akun hutang, sementara modal bank yang merupakan unsur dalam menghitung CAR pada neraca berada di ekuitas. Perbedaan posisi pada neraca inilah yang menyebabkan LDR tidak berpengaruh signifikan terhadap CAR. Kecilnya nilai likuiditas yaitu 72,28\% menyebabkan tidak berpengaruh terhadap modal perusahaan, seharusnya melalui likuiditas yang tinggi akan meningkatkan permodalan. Hal ini terjadi karena sebagian besar modal BPR terkonsentrasi pada Simpanan Pihak Ketiga dalam bentuk kas, sayangnya dalam hal ini kemampuan bayar BPR di NTB rendah. Rendahnya kemampuan bayar ini salah satunya disebabkan oleh pengerahan harta yang dimiliki untuk kegiatan lain misalnya meningkatnya penjualan dan pendapatan.

\subsubsection{Pengaruh Kemampuan Bayar Terhadap Modal Melalui Kemampulabaan}

Berdasarkan hasil analisis jalur pada Gambar 1 dapat dijelaskan bahwa Kemampuan bayar berpengaruh secara tidak langsung bersifat negatif terhadap modal melalui kemampulabaan. Hasil ini Mendukung Umar (2017) yang menyatakan adanya trade-off likuiditas terhadap modal. Beberapa pendapat lain mengatakan likuiditas yang tinggi akan meningkatkan modal, karena likuiditas akan meningkatkan profitabilitas, dan profitabilitas yang tinggi akan meningkatkan modal.

Kemampuan bayar pada penelitian ini di proksikan dengan LDR. LDR merupakan rasio perbandingan antara jumlah dana yang disalurkan ke masyarakat (kredit) dengan jumlah dana masyarakat dan modal sendiri yang digunakan. Rendahnya likuiditas yang dimiliki oleh BPR di NTB, akan tetapi profitabilitas BPR tetap tinggi yaitu diatas 1,25\%, hal ini terjadi karena adanya efisiensi, jadi dengan profitabilitas yang tinggi akan meningkatkan permodalan BPR. Hal tersebut didukung oleh Putra, dkk. (2018) yang menyatakan sebanyak 23 BPR di NTB masih tergolong kecil ditinjau dari total asset dan pendapatan yang diperoleh. Selain hal tersebut jika dibandingkan dari aturan yang ada nilai LDR masih dibawah standar. Hasil tersebut merekomendasikan model penelitian bahwa kemampulabaan sebagai variabel yang pure intervening. Kemampuan bayar yang rendah merupakan salah satu wujud upaya perusahaan untuk melakukan penghematan dan efisiensi karena dapat menekan biaya yang muncul dan dapat digunakan pada investasi pada hal yang produktif lainnya dalam menghasilkan return.

\section{KESIMPULAN DAN SARAN}

\subsection{Kesimpulan}

Berdasarkan hasil analisis data tentang pengaruh kemampuan bayar terhadap modal dengan kemampulabaan sebagai variabel intervening pada BPR di Nusa Tenggara Barat, dapat disimpulkan bahwa:

1. Hasil penelitian menunjukkan kemampuan bayar tidak berpengaruh secara langsung terhadap modal. Hal ini dikarenakan kemampuan bayar yang dimiliki BPR rendah, sedangkan sebagian besar modal bersumber pada kas perusahaan. Kemampuan bayar yang rendah disebabkan oleh pengerahan sumber daya (aset) untuk kegiatan lain misalnya mengejar pendapatan.

2. Hasil penelitian menunjukkan kemampuan bayar berpengaruh secara tidak langsung terhadap modal melalui kemampulabaan dan memiliki hubungan yang negatif. Rendahnya kemampuan bayar disatu sisi, namun memiliki kemampulabaan yang tinggi 
yaitu diatas 1,25\%, hal ini terjadi karena adanya efisiensi, jadi dapat disimpulkan bahwa dengan profitabilitas yang tinggi akan meningkatkan permodalan BPR dan ternyata sebagian besar BPR di NTB tergolong kecil. Kemampuan bayar yang tinggi merupakan hal yang dianggap pemborosan bagi perusahaan karena merupakan idle capacity (kapasitas menganggur). Kelebihan kapasitas bayar akan menimbulkan biaya yang tidak sebanding dengan return (pengembalian) yang diperoleh BPR. Jadi, BPR tidak perlu khawatir dengan kemampuan bayar yang rendah, karena permodalan akan meningkat dengan syarat menjaga efisiensi.

\subsection{Saran}

Implikasi dari penelitian ini adalah agar Bank Perkreditan Rakyat (BPR) dapat meningkatkan nilai likuiditas dalam rangka memperbesar modal secara langsung dan secara tidak langsung melalui kemampulabaan, karena sebagian besar modal dibentuk oleh kas atau Dana Pihak Ketiga (DPK).

\section{DAFTAR PUSTAKA}

Adelopo, I., Lloydking, R., Tauringana, V. (2018). Determinants of bank profitability before, during, and after the financial crisis", International Journal of Managerial Finance, 1-21.

Afriyeni. (2017). Profitabilitas BPR di Kota Padang ditinjau dari Rasio Likuiditas, Jurnal Benefia, 2(1) Februari 2017, 22-32.

Andini, F. dan Yunita, I. (2015). Analisis pengaruh ROA, ROE, NPL, dan LDR terhadap Capital Adequacy Ratio (CAR) pada perusahaan perbankan di Indonesia (Studi Kasus Pada Bank Umum Indonesia yang Terdaftar di Bursa Efek Indonesia Periode 2009-2013). Jurnal e-Procedding of management : vol.2, No. 2 Agustus 2015.

Li, F., dan Saiz, H.P. (2018). Measuring Systemic Risk Across Financial Market Infrastructures, Journal of Financial Stability, 34, 1-11.

Putra, I N.N.A. (2012). Kepemilikan Manajerial dan Risiko Kredit Sebagai Pemicu Biaya Keagenan Pada Lembaga Keuangan Mikro, Jurnal Keuangan dan Perbankan, vol.16, no.3, 437-444.

Putra, I.N.N.A., (2013), Perbedaan Profitabilitas dan Tingkat Pengawasan Sebelum dan Sesudah Merger Pada Bank Perkreditan Rakyat, Jurnal Keuangan dan Perbankan, vol.17, no.2, 302-309.

Putra, I.N.N.A., Sakti, D.P.B., Mandra, I.G., Bisma, I.D.G, Oktaryani, G.A.S., (2018), Perbedaan Karakteristik BPR Kecil dan BPR Menengah di Nusa Tenggara Barat, Distribusi, Vol.6 , No.2 , 24-34

Putra, I.N.N.A., Mannan, S.S.A., Gumanti, T.A., Sukendri, N. (2019), The effect of managerial ownership on liquidity, agency cost and performance of credit society banks in West Nusa Tenggara Province of Indonesia, Business Innovation and Development in Emerging Economies: Proceedings of the 5th Sebelas Maret International Conference on Business, Economics and Social Sciences (SMICBES 2018), July 17-19, 2018, Bali, Indonesia.

Putra, I.N.N.A., Manan, A., Martiningsih, R.S.P., (2019), Mengukur Kinerja BUMDesa, Pusat Data Informasi, Badan Penelitian dan Pengembangan, Pendidikan dan Pelatihan, dan Informasi (BALILATFO) Kementerian Desa, Pembangunan Daerah Tertinggal dan Transmigrasi, Jakarta.

Ramlall, I. (2019), A Framework for Financial Stability Risk Assessment in Banks, In The Banking Sector Under Financial Stability. Book Chapters, 29-117. 
Sahyouni, A., \& Wang, M. 2019, Liquidity creation and bank performance: evidence from MENA", ISRA International Journal of Islamic Finance, 1-19.

Sarath, D., \& Pham D.V. 2015, The determinants of Vietnamese banks' lending behavior, Journal of Economic Studies, Vol. 42 Iss 5 pp. 861 - 877.

Sari dkk. (2016). Analisis pengaruh kualitas aset, likuiditas, rentabilitas, dan efisiensi terhadap rasio kecukupan modal perbankan yang terdaftar di Bursa Efek Indonesia. Jurnal Universitas Bengkulu, vol.4 No.2:1-15.

Sembiring, S., (2010), Himpunan Peraturan Perundang-undangan Republik Indonesia "Bank Perkreditan Rakyat" (BPR), Penerbit Nuansa Aulia, Bandung.

Sulaiman, A.A., Mohamad, Mohamad, M.T., Hashim, S.A, (2018). Islamic Versus Conventional Banking, In New Developments in Islamic Economics. Published online: 22 Oct 2018; 119-214.

Umar, M., Sun, G., Majeed, M.A., (2017). Bank capital and liquidity creation: Evidence of relation from India, Journal of Asia Business Study, Vol.11, Iss.2

Valencia, O.C. dan Bolanos A.O. (2018). Bank Capital Buffers Arround The World: Cyclical Patterns and The Effect of Market Power, Journal of Financial Stability, 1-13. 